\title{
EVALUATION OF ANTERIOR MAXILLARY HORIZONTAL RIDGE AUGMENTATION WITH SIMULTANOUS IMPLANT PLACEMENT USING CERABONE® VERSUS CERABONE® COMBINED WITH PLATELET RICH PLASMA (RANDOMIZED CLINICAL TRIAL)
}

\author{
Ahmed M. Ibrahim ${ }^{1 *} B D S$, Mervat M. Khalil² $P h D$, Gaafar N. El Halawani ${ }^{3} P h D$,
}

\begin{abstract}
INTRODUCTION: Rehabilitation of the anterior maxilla using dental implants is frequently problematic because of the deficiency of alveolar ridge width. Under certain conditions ridge augmentation with simultaneous implant placement is recommended.

OBJECTIVES: To evaluate horizontal augmentation of narrow anterior maxillary alveolar ridge with simultaneous implant placement using Cerabone ${ }^{\circledR}$ with and without platelet rich plasma (PRP).

MATERIALS AND METHODS: In this study, 14 implants were placed in patients with insufficient alveolar ridge width in the maxillary lateral incisor region. Patients were divided into two groups; In Group “1” Cerabone ${ }^{\circledR}$ only was used as an augmentation material while in Group “2” a mixture of Cerabone ${ }^{\circledR}$ and PRP was used. A collagen membrane was used to cover the grafting material. Postoperative pain was assessed using visual analogue scale. Healing and postoperative edema were evaluated. Cone Beam Computed Tomography (CBCT) was obtained before surgery, immediately postoperatively and after 6 months so that the labial bone width and bone density were evaluated. Osstell was used to evaluate implant stability quotient (ISQ) during surgery and after 6 months.

RESULTS: All implants in both groups were successfully osseointegrated and functionally stable. No significant difference in postoperative pain, edema or wound healing was detected between the two groups. The mean percentage of change in ISQ was superior in Group "2" when compared to Group " 1 ”, but statistically there was no significant difference ( $\mathrm{P}=0.898)$. The labial bone width in Group "2" was significantly higher than that of Group “1” $(\mathrm{P}=0.002)$. The mean percentage of change in labial bone density was $57.95 \%$ in Group " 1 ” and $112.52 \%$ in Group "2” $(\mathrm{P}=0.848)$.

CONCLUSION: Cerabone ${ }^{\circledR}$ can be used effectively for guided bone regeneration around dental implant in narrow maxillary anterior alveolar ridges. Moreover, the addition of PRP has a positive effect on bone regeneration around implants.

KEYWORDS: Ridge Augmentation, Xenograft, Cerabone, PRP.

RUNNING TITLE: Platelet Rich Plasma and Guided Bone Regeneration.

${ }^{1}$ BDS,2008, Faculty of Dentistry, Alexandria University, Egypt.

${ }^{2}$ Professor of Oral and Maxillofacial Surgery, Department of Oral and Maxillofacial Surgery Faculty of Dentistry, Alexandria University, Egypt.

${ }^{3}$ Lecturer of Oral and Maxillofacial Surgery, Department of Oral and Maxillofacial Surgery Faculty of Dentistry, Alexandria University, Egypt.

* Corresponding Author:

E-mail: doctor_ai_2@yahoo.com
\end{abstract}

\section{INTRODUCTION}

Loss of alveolar ridge width is a common problem that interferes with rehabilitation of the maxillary anterior region using dental implants. A successful implant should be surrounded by minimum thickness of $1-1.5 \mathrm{~mm}$ of bone on both the labial and lingual aspects of the implant. Ideal alveolar ridge width should be at least $5 \mathrm{~mm}$ (1).

Several techniques are preformed to manage deficient ridge width including guided bone regeneration, ridge splitting, block bone grafting, and distraction osteogenesis. A ridge width of $3.5-4 \mathrm{~mm}$ could be managed by guided bone regeneration while severe width deficiency (less than $3.5 \mathrm{~mm}$ ) should be managed differently by block bone grafting.

The presence of adequate primary stability is essential for ridge augmentation with simultaneous implant placement
(Sandwich Bone Augmentation) otherwise implant placement should be delayed 4-6 months after grafting (Staged Guided Bone Regeneration) (2).

Different types of bone grafting materials are available for guided bone regeneration. Bone grafts are classified into autografts, allografts, xenografts and alloplastic synthetic bone substitutes. Each type has some advantages and disadvantages. Autograft is taken from a donor site from the same patient and has many advantages including its osteoinductive osteoconductive effect and the absence of the risk of infection. The main disadvantage is the need for a second surgery at the donor site and rapid resorption during the healing phase (3). Although a second surgery is avoided, the transmission of infection is the main disadvantage of Allografts and xenografts (4). On the contrary, alloplastic synthetic grafting materials 
eliminate both the risk of infection and the need for a second surgery at the donor site.

Cerabone ${ }^{\circledR}$ is a bovine xenograft bone substitute that has been used in dental application since 2002. It is considered to be a reliable, safe and stable bone substitute (5). Cerabone ${ }^{\circledR}$ is similar to human bone regarding surface porosity and chemical composition. The material is highly porous and contains numerous interconnected pores, so it acts as a scaffold that allow penetration and bone ingrowth.

During manufacture, the material is subjected to high temperature more than $1200{ }^{\circ} \mathrm{C}$ eliminating all organic components and thus minimizing the risk of disease transmission (6).

Rapid new bone formation has been proven by several studies. An experimental study on critical size defect in rabbits has shown that cerabone ${ }^{\circledR}$ was replaced with a median of $55 \%$ of newly formed bone after 8 weeks (7).

Application of cerabone ${ }^{\circledR}$ in dental practice includes Sinus lift, horizontal and vertical augmentation, peri-implant defects, socket preservation, bone defect augmentation and periodontal defects.

Platelet rich plasma is a blood derivative that contains high concentration of platelets and many growth factors that enhance tissue regeneration (8). It has been suggested that adding platelet rich plasma to the grafting material enhance osteointegration around implants and increase bone density (9). This study was conducted to evaluate the effectiveness of Cerabone ${ }^{\circledR}$ with and without platelet rich plasma as an augmentation material with simultaneous implant placement in the anterior maxillary region.

\section{MATERIALS AND METHODS}

The clinical part of the study was performed after acquiring the ethical clearance from the Research Ethics Committee, Faculty of Dentistry, Alexandria University. All patients signed an informed consent form before undergoing the operation to ensure their understanding of the outcome and risks of the operation.

This randomized clinical trial has been conducted on patients in need for implant placement at their lost anterior maxillary lateral incisors. Fourteen patients were divided into two groups, in Group " 1 " seven patients received an implant grafted with cerabone ${ }^{\circledR}$ only while in Group " 2 " seven patients received an implant grafted with both cerabone ${ }^{\circledR}$ and PRP.

Patients in this study were selected from the outpatient clinic of Oral and Maxillofacial Surgery Department, Faculty of Dentistry, Alexandria University. Patients were chosen according to the following criteria: Good oral hygiene, age between 30 - 50 years old, no gender preference, alveolar ridge width of $3-4 \mathrm{~mm}$ at the site of implantation and ridge height not less than $12 \mathrm{~mm}$.

\section{Materials}

- Cerabone ${ }^{\circledR}$ 0.5-1.0 mm (botiss biomaterials, Germany): A xenograft bone substitute that originates from bovine cancellous bone from New Zealand cattle; Cerabone ${ }^{\circledR}$ is composed of $100 \%$ pure hydroxyapatite with porosity 65 $80 \%$ and mean pore size $600-900 \mu \mathrm{m}$.

- Dentium super line implant system (Dentium, Korea): A conventional, two-piece, screw-type titanium dental implant with round tapered design. A standardized implant size having length of $12 \mathrm{~mm}$ and $3.6 \mathrm{~mm}$ diameter were used in this study.
- Dentium collagen membrane (Dentium, Korea): A membrane composed of highly pure type I collagen with $0.3 \mathrm{~mm}$ thickness.

- Osstell ISQ Monitor (Osstell AB, Gothenburg, Sweden) has been used to evaluate implant stability quotient (ISQ) through resonance frequency analysis.

- A low speed centrifuge LC-04R (Syntific System, China) has been used for preparation of platelet rich plasma PRP with maximum speed 4000 rotation per minute RPM, maximum relative centrifugal force RCF 1790xg and rotor capacity $20 \mathrm{ml}$ x6.

\section{Methods:}

\section{Preoperative phase}

Preoperative evaluation was done through history taking and careful clinical examination by inspection and palpation. Radiographic evaluation was done by performing an orthopantomogram for each patient, followed by CBCT.

\section{Preparation of platelet rich plasma}

After identification of median cubital vein, a $9 \mathrm{ml}$ of blood were drawn from the patient into a standardized $10 \mathrm{ml}$ syringe. One millimetre of anticoagulant dextrose solution (ACD) were added. Two disposable $5 \mathrm{ml}$ syringes were prepared for the first centrifugation by cutting their finger-holders with scissors. Four milliliters of the whole blood were transferred into each syringe and centrifuged at $3000 \mathrm{rpm}$ for 3 minutes. Red blood cells were separated from plasma. Plasma was aspirated and transferred to another syringe by an extension tube. The second centrifugation was performed at $4000 \mathrm{rpm}$ for 15 minutes and plasma was separated into platelet poor plasma PPP at the upper 2/3 and platelet rich plasma PRP at the lower third. Platelet poor plasma PPP was discarded and platelet rich plasma PRP became ready.

\section{Operative phase}

All patients were operated under local anaesthesia. Paracrestal incision was done down to the bone with blade no.15. The incision was done extending from the mesial aspect of the maxillary central incisor to the distal aspect of the canine. Elevation of mucoperiosteal flap was achieved using a periosteal elevator. According to the manufacturer's instructions, sequential drilling was done to achieve the desired width at the osteotomy site. Implant fixture was placed at the osteotomy site using torque wrench. The Smartpeg was fixed to the implant and the Osstell was used to measure the Implant Stability Quotient (ISQ).

In Group " 1 " Cerabone ${ }^{\circledR}$ was applied on the exposed labial surface of implant while in Group " 2 " a mixture of cerabone ${ }^{\circledR}$ and platelet rich plasma PRP was applied. A Collagen membrane was placed in both groups and fixed in place by the implant cover screw (Figures 1\&2). Flap was repositioned and closed using interrupted sutures. Postoperative instructions were given to all patients. Medications were prescribed including antibiotic, non-steroidal anti-inflammatory and mouthwash.

\section{Follow-up phase}

A thorough Follow-up was performed up to six months postoperatively for the assessment of the following clinical parameters: postoperative pain, edema, wound healing, implant stability, labial bone width and density.

Postoperative pain was assessed through the visual analogue scale (VAS); the severity of pain was expressed in the form of numbers ranging from zero (representing absence of pain) to ten (representing the most severe pain). Features that were 
observed during wound healing include swelling, redness, hotness, pus discharge, and wound dehiscence. In order to evaluate postoperative edema, the examiner's finger was pressed into dependant area of patient skin for 5 seconds. The finger left an impression when removed. The pitting was graded on a scale from +1 to +4 .
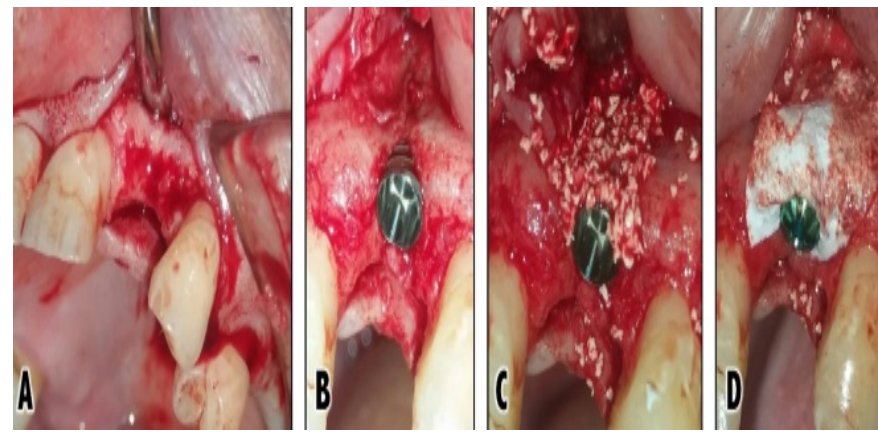

Figure (1): Operative steps in the control group: A) Elevation of mucoperoisteal flap. B) Implant fixture in place. C) Application of the grafting material. D) Application of collagen membrane
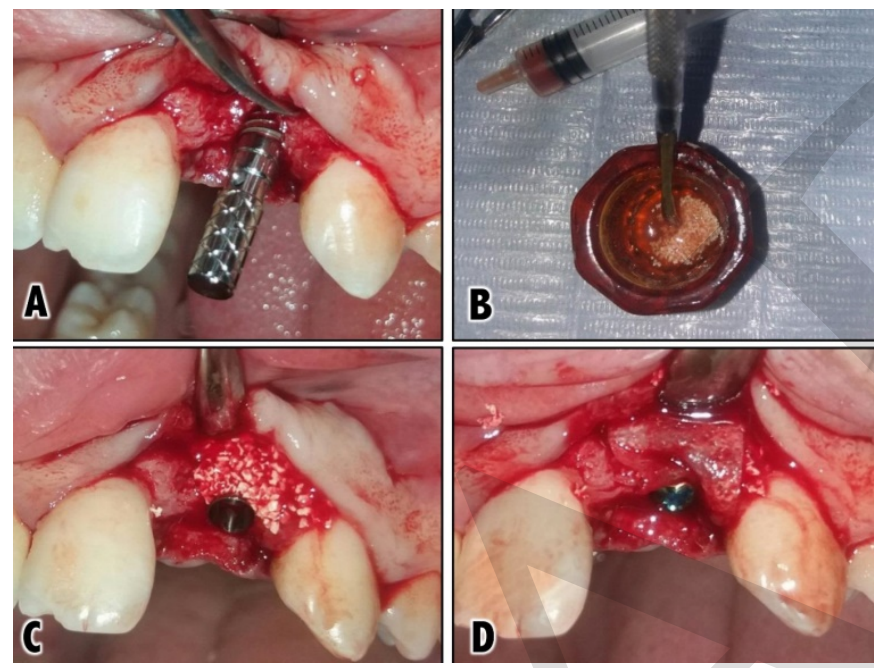

Figure (2): Operative steps in the study group: A) Implant fixture in place. B) Mixing PRP with the grafting material. C) Application of the mixture on the exposed implant surface. D) Application of collagen membrane.

Implant stability was measured by the Osstell device immediately post-operative and after six months. The result was presented as an ISQ value of 1-100. The higher the ISQ, the more stable the implant.

A CBCT was obtained preoperatively, immediately postoperatively, and after six months postoperative. Measurement of labial bone thickness was done once after six months postoperatively by OnDemand3 $\mathrm{D}^{\mathrm{TM}}$ software. This was done by using the ruler function from the measure section of the tool bar. This was done at two fixed points along the labial surface of the implant. (Figure 3)

The software OnDemand3D ${ }^{\mathrm{TM}}$ was used for image reconstruction. Bone density was evaluated on the labial aspect of the implant. This was done by selecting the profile function from the measure section of the tool bar. Bone density was measured along a line extending parallel to the labial surface of implant. The software displayed the mean, minimum and maximum bone density readings. Bone density was measured in Hounsfield unit (HU) which represents a scale of radiodensity.
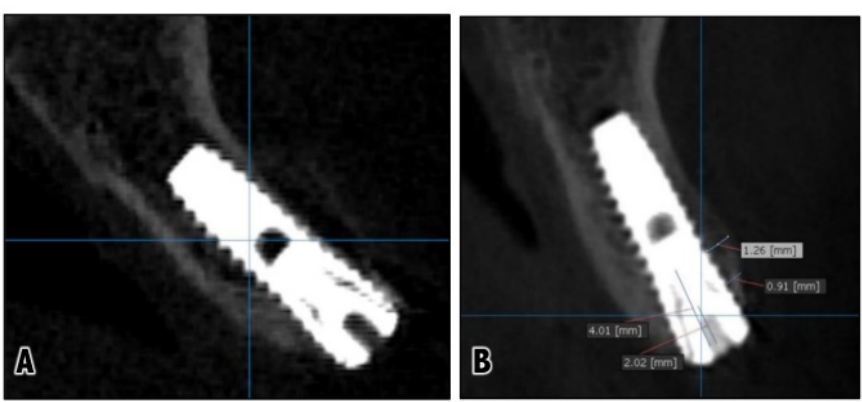

Figure (3): Radiographic evaluation through CBCT:

A) Immediately postoperative.

B) Evaluation of labial bone width six months postoperative at two fixed points.

\section{Prosthetic phase}

After a healing period of six months, a second stage surgery was performed using a soft tissue punch to expose and remove the implant covering screw. The healing abutment was attached to the implant to allow soft tissue contouring. After two weeks, the healing abutment was removed and the abutment was screwed in place. A rubber base impression was taken to make a porcelain fused to metal restoration.

\section{Statistical analysis}

All the obtained data was statistically analysed and presented in the form of tables, graphs and charts using the IBM Statistical Package for Social Science (SPSS) software version 22.0 (SPSS ver.22 Chicago, IL, USA). Data were described using mean, median, and range. Qualitative variables were described using frequency and percentage. Nonparametric tests were applied.

Mann Whitney U test was used to compare the parameters (pain score, edema, bone density, bone width, and implant stability) between the two groups. Wilcoxon Signed Rank test was used to test the difference between the parameters (bone density and implant stability) immediately postoperative and after 6 months at the same group.

Results were represented graphically by Bar graphs, which illustrates the mean value of the parameters. In all statistical tests, a level of significance of .05 was used, below which the results were considered to be statistically significant.

\section{RESULTS}

This study included fourteen patients [8 males and 6 females] of ages ranging from $30-49$ years. They were selected from Outpatient Clinic of the Oral and Maxillofacial Surgery Department, Faculty of Dentistry, Alexandria University. All patients received an implant with dimension $3.6 \mathrm{~mm}$ diameter and $12 \mathrm{~mm}$ length at maxillary lateral incisor region. All patients were followed up both clinically and radiographically for six months.

Pain was evaluated three days postoperatively using the visual analogue scale (VAS). Ten patients experienced mild pain (VAS=1-4) and four patients experienced moderate pain (VAS=5-7). The mean of VAS at group " 1 " was 4.14 and at group "2" was 3.14. However, statistically there was no significant difference $(\mathrm{P}=0.284)$. 
All patients were observed for any postoperative complications. Only three patients experienced wound dehiscence and edematous discharge that was resolved within two weeks postoperatively. No serious complications were noticed regarding wound infection and implant failure.

Regarding postoperative edema, four patients of the control group and two patients of the study group presented a slight indentation $(+2)$ that rebounded within 15 seconds and the remaining patients showed a barely detectable edema $(+1)$. However, statistically there was no significant difference between the study and control group $(\mathrm{P}=0.298)$

Implant stability quotient (ISQ) was evaluated in all patients of both groups after implant placement and after the 6-month healing period using the Osstell device. Data were collected and analyzed. For Group " 1 ”, the mean of ISQ after implant placement was 62.7 and there was an increase after six months postoperative reaching 70.2 and statistically there was a significant difference $(\mathrm{P}=0.017)$. For Group “ 2 ”, the mean of implant stability quotient after implant placement was 64.5 and there was an increase after six months postoperative reaching 73. Statistically there was a significant difference $(\mathrm{P}=0.027)$. The mean percentage of change in ISQ after six months postoperative was found to be higher in Group " 2 " (13.81\%) when compared to Group “1” (12.84\%). However, statistically there was no significant difference $(p=0.898)$. (Table 1).

Table (1): Comparison between the percentage of change in ISQ at group " 1 ” and group “2” during six months postoperative.

\begin{tabular}{|c|c|c|c|c|}
\hline & \multicolumn{2}{|c|}{$\begin{array}{l}\text { Group 1 } \\
\end{array}$} & \multirow[b]{2}{*}{$\mathbf{Z}$} & \multirow[b]{2}{*}{$\mathbf{P}$} \\
\hline ISQ value & $\begin{array}{c}\text { Immediate } \\
\text { postoperative }\end{array}$ & $\begin{array}{c}\text { After six months } \\
\text { postoperative }\end{array}$ & & \\
\hline \multirow[t]{2}{*}{$\begin{array}{c}\text { Min - Max } \\
\text { Mean } \\
\text { Median }\end{array}$} & $\begin{array}{c}53-73 \\
62.7 \\
62\end{array}$ & $\begin{array}{c}65-75 \\
70.2 \\
70\end{array}$ & 2.38 & $0.017^{*}$ \\
\hline & \multicolumn{2}{|c|}{ Group 2} & & \\
\hline ISQ value & $\begin{array}{c}\text { Immediate } \\
\text { postoperative }\end{array}$ & $\begin{array}{c}\text { After six months } \\
\text { postoperative }\end{array}$ & $\mathbf{Z}$ & $\mathbf{P}$ \\
\hline $\begin{array}{c}\text { Min - Max } \\
\text { Mean } \\
\text { Median } \\
\end{array}$ & $\begin{array}{c}57-75 \\
64.5 \\
64 \\
\end{array}$ & $\begin{array}{c}69-76 \\
73 \\
74 \\
\end{array}$ & 2.2 & $0.027 *$ \\
\hline $\begin{array}{c}\text { ISQ } \\
\text { (\% change) }\end{array}$ & Group 1 & Group 2 & $\mathbf{U}$ & $\mathbf{P}$ \\
\hline $\begin{array}{l}\text { Min - Max } \\
\text { Mean } \\
\text { Median }\end{array}$ & $\begin{array}{c}1.43-22.64 \% \\
12.84 \% \\
11.29 \%\end{array}$ & $\begin{array}{c}0-31.58 \% \\
13.81 \% \\
11.29 \%\end{array}$ & 23.5 & 0.898 \\
\hline
\end{tabular}

U, p: U and P values for Mann Whitney U test

$\mathrm{Z}, \mathrm{P}: \mathrm{Z}$ and $\mathrm{P}$ values for Wilcoxon signed rank test

*: Statistically significant at $\mathrm{p} \leq 0.05$

Data were collected after six months postoperative from all the patients in both groups regarding the width of bone at the labial surface of the implant at two fixed points. The mean labial bone width at point 1 was found to be significantly higher in Group " 2 " when compared with Group " 1 " $(\mathrm{P}=0.002)$. In addition, there was a statistically significant difference between both groups at point $2(\mathrm{P}=0.015)$ (Figure 4 \& Table 2).

The mean of bone density labial to the implant was assessed in both groups immediately postoperative and after six months postoperative. In Group " 1 ", the mean immediate postoperative labial bone density was (663 HU) and increased after six months (997 HU). This increase has been found to be statistically significant $(\mathrm{P}=0.018)$. Regarding Group " 2 ”, the mean immediate postoperative labial bone density was (778
HU) and increased after six months to (1300 HU). This increase has been found to be statistically significant $(\mathrm{P}=0.018)$. The mean percentage of change in labial bone density after six months postoperative was found to be higher in Group "2" (112.52\%) when compared to Group " 1 " (57.95\%). However, statistically there was no significant difference ( $\mathrm{p}=0.848)$. (Figure 5 \& Table 3$)$.

Table (2): Comparison between labial bone width at group "1" and group " 2 " when measured at two fixed points.

\begin{tabular}{|c|c|c|c|c|c|c|c|c|}
\hline & \multicolumn{4}{|c|}{ Point 1} & \multicolumn{4}{|c|}{ Point 2} \\
\hline \begin{tabular}{|c} 
Labial \\
bone \\
width
\end{tabular} & $\begin{array}{c}\text { Group } \\
1\end{array}$ & $\begin{array}{c}\text { Grou } \\
\text { p } 2\end{array}$ & $\mathbf{U}$ & $\mathbf{P}$ & $\begin{array}{c}\text { Grou } \\
\text { p } 1\end{array}$ & $\begin{array}{c}\text { Grou } \\
\text { p } 2\end{array}$ & $\mathbf{U}$ & $\mathbf{P}$ \\
\hline $\begin{array}{l}\text { Min - } \\
\text { Max } \\
\text { Mean } \\
\text { Median }\end{array}$ & $\begin{array}{c}0.9-1.24 \\
\mathrm{~mm} \\
1.08 \mathrm{~mm} \\
1.11 \mathrm{~mm}\end{array}$ & $\begin{array}{r}1.48- \\
2.37 \mathrm{~mm} \\
1.93 \mathrm{~mm} \\
1.9 \mathrm{~mm}\end{array}$ & 0 & $0.002 *$ & $\begin{array}{c}1.2- \\
1.88 \mathrm{~mm} \\
1.52 \mathrm{~mm} \\
1.58 \mathrm{~mm}\end{array}$ & $\begin{array}{c}1.57- \\
2.47 \mathrm{~mm} \\
2.02 \mathrm{~mm} \\
2 \mathrm{~mm}\end{array}$ & 5.5 & $0.015 *$ \\
\hline
\end{tabular}

$\mathrm{U}$, p: $\mathrm{U}$ and $\mathrm{P}$ values for Mann Whitney $\mathrm{U}$ test

*: Statistically significant at $\mathrm{p} \leq 0.05$

Table (3): Comparison between the percentage of change in labial bone density at group " 1 " and group " 2 " during six months postoperative.

\begin{tabular}{|c|c|c|c|c|}
\hline \multirow[b]{2}{*}{$\begin{array}{l}\text { Labial bone } \\
\text { density }\end{array}$} & \multicolumn{2}{|c|}{ Group 1} & \multirow[b]{2}{*}{$\mathbf{Z}$} & \multirow[b]{2}{*}{$\mathbf{P}$} \\
\hline & $\begin{array}{c}\text { Immediate } \\
\text { postoperative }\end{array}$ & $\begin{array}{c}\text { After } \\
\text { six months }\end{array}$ & & \\
\hline $\begin{array}{l}\text { Min - Max } \\
\text { Mean } \\
\text { Median }\end{array}$ & $\begin{array}{c}480-957 \mathrm{HU} \\
663.8 \mathrm{HU} \\
574 \mathrm{HU}\end{array}$ & $\begin{array}{c}794-1174 \\
\text { HU } \\
997 \mathrm{HU} \\
1013 \mathrm{HU}\end{array}$ & 2.3 & $0.018 *$ \\
\hline \multirow{2}{*}{$\begin{array}{l}\text { Labial bone } \\
\text { density }\end{array}$} & \multicolumn{2}{|c|}{ Group 2} & & \\
\hline & $\begin{array}{c}\text { Immediate } \\
\text { postoperative }\end{array}$ & $\begin{array}{c}\text { After } \\
\text { six months }\end{array}$ & $\mathbf{Z}$ & $\mathbf{P}$ \\
\hline $\begin{array}{l}\text { Min - Max } \\
\text { Mean } \\
\text { Median }\end{array}$ & $\begin{array}{c}235-1154 \mathrm{HU} \\
778.7 \mathrm{HU} \\
850 \mathrm{HU}\end{array}$ & $\begin{array}{c}1091-1663 \\
\text { HU } \\
1300 \mathrm{HU} \\
1286 \mathrm{HU}\end{array}$ & 2.3 & $0.018 *$ \\
\hline $\begin{array}{c}\text { Labial bone } \\
\text { density } \\
\text { (\% change) }\end{array}$ & Group 1 & Group 2 & $\mathbf{U}$ & $\mathbf{p}$ \\
\hline $\begin{array}{l}\text { Min - Max } \\
\text { Mean } \\
\text { Median }\end{array}$ & $\begin{array}{c}5.85-117.92 \% \\
57.95 \% \\
63.55 \%\end{array}$ & $\begin{array}{c}18.28-447.23 \\
\% \\
112.52 \% \\
67.29 \% \\
\end{array}$ & 23 & 0.848 \\
\hline
\end{tabular}

$\mathrm{U}, \mathrm{p}$ : $\mathrm{U}$ and $\mathrm{P}$ values for Mann Whitney $\mathrm{U}$ test

$\mathrm{Z}, \mathrm{P}: \mathrm{Z}$ and $\mathrm{P}$ values for Wilcoxon signed rank test

*: Statistically significant at $\mathrm{p} \leq 0.05$

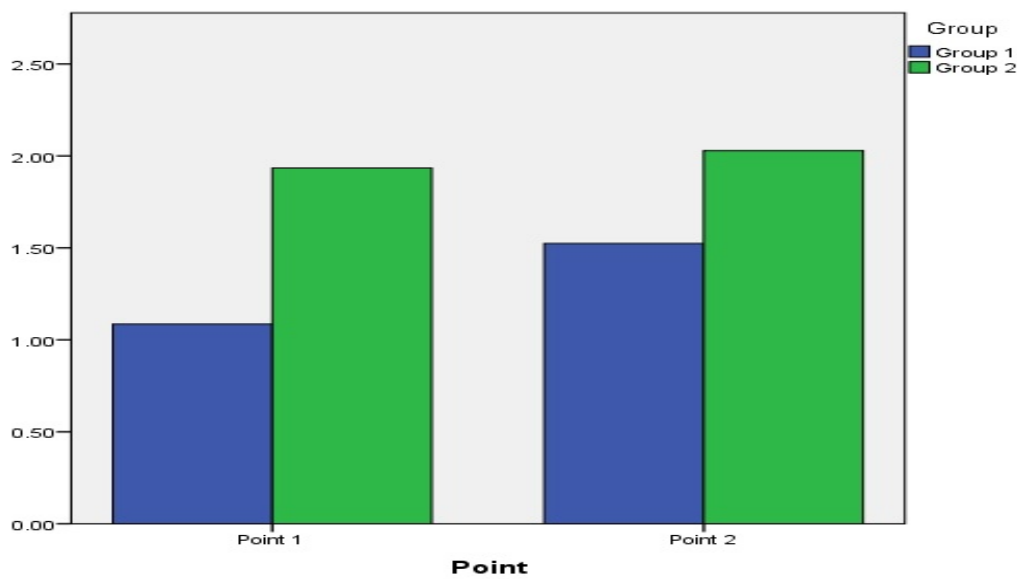

Figure (4): Comparison between the mean labial bone width in Group " 1 " and Group " 2 " when measured at two fixed points. 


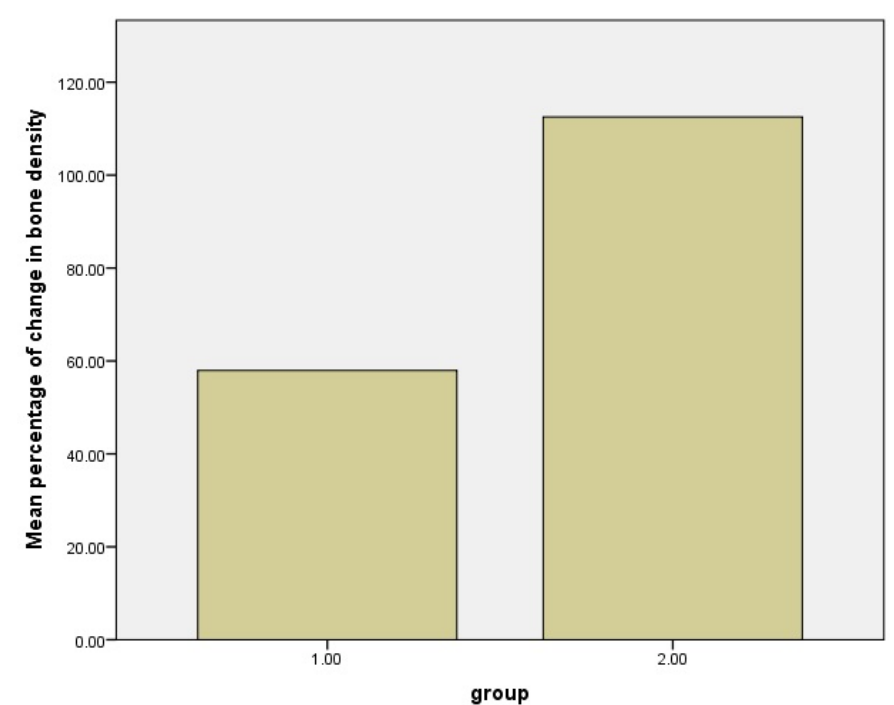

Figure (5): Comparison between the mean percentage of change in bone density at Group " 1 " and Group "2" during six months postoperative.

\section{DISCUSSION}

This study is a randomized prospective clinical trial that aimed to evaluate the effect of adding platelet rich plasma PRP to a bovine xenograft cerabone ${ }^{\circledR}$ when used as augmentation material around dental implants in narrow anterior maxillary alveolar ridge.

The surgical technique that was used in this study is horizontal ridge augmentation with simultaneous implant insertion. According to Christensen, et al. (10) such technique provides predictable treatment outcomes. However, the staged approach is still considered less risky but also time consuming and requires multiple surgeries. Moreover, Fairbairn and Leventis (11) suggested that this surgical protocol offers long-term successful outcomes regarding guided bone regeneration.

The implant system that was adopted in this trial is a reliable Korean system that is characterized by double threaded tapered body design and sandblasted acid etched surface. Lee et al. (12) preformed a five years retrospective clinical study on 249 dentium implants and the results showed $97.37 \%$ survival rate.

A natural bovine xenograft cerabone ${ }^{\circledR}$ was used as augmentation material in this study. Cerabone ${ }^{\circledR}$ is a potent osteoconductive bone grafting material that promotes angiogenesis and bone remodeling. Caiazzo, et al. (13) used cerabone ${ }^{\circledR}$ as augmentation material to fill defects around immediately placed implants in the esthetic zone and the results showed successful functional and esthetic outcome six months postoperative.

Moreover, Forna, et al. (14) preformed horizontal guided bone regeneration on 40 patients and concluded that cerabone ${ }^{\circledR}$ covered with collagen membrane is a reliable successful treatment concept.

For estimating the effect of adding platelet rich plasma to cerabone ${ }^{\circledR}$ on the outcomes of guide bone regeneration, we used a new technique for preparing platelet rich plasma. This technique is based on modifying disposable $5 \mathrm{ml}$ syringes to allow their insertion into the centrifuge machine. This method is not only economic but also allows easy handling and separation of platelet rich plasma. The first centrifugation was done at $3000 \mathrm{rpm}$ in order to shorten the time down to 3 minutes. The speed and time in the second centrifugation should be as high and long as possible to allow more platelets to precipitate, so it was done at a maximum speed of $4000 \mathrm{rpm}$ for 15 minutes (15).

The parameters that were evaluated in this study included postoperative pain, edema, wound healing, implant stability, labial bone width and bone density.

The results of this study have shown no significant difference in postoperative pain, edema or wound healing between the two groups. These post-operative complications seem to be more affected by the amount of surgical trauma than by the composition of graft material. This result corresponds to other studies, which suggests that platelet rich plasma does not significantly accelerate a non-complicated wound healing (16).

Implant stability plays a major role in dental implant success as it eliminates micro-movement at the bone implant interface, thus promoting osteointegration (17).

Osstell is a diagnostic tool that estimates implant fixture resistance to vibration through resonance frequency analysis. This resistance is transformed into a value from 1 to 100 which represents the implant stability quotient ISQ. Several studies showed that Osstell is an accurate reliable tool for the evaluation of implant stability $(18,19)$.

In this study, the implant stability quotient ISQ was evaluated after implant placement and after six months postoperative in both groups. The result showed that ISQ did increase significantly during the healing period in both groups. Although, the mean percentage of change in ISQ was superior in the study group after 6 months postoperative but statistically there was no significant difference between the study and control group. However, this could be a result of limited sample size.

In accordance with this result, Monov, et al. (20) found in their study that PRP had increased the implant stability in the study group. However, statistically there was no significant difference. Furthermore, a recent 3-year follow-up study has been conducted on 32 patients to estimate the effect of platelet rich plasma PRP on the implant stability quotient ISQ. The results showed no significant difference between the two groups (21).

Gopinath, et al. (22) concluded that the positive effect of PRP could be noticed in the early stages after surgery, as normal bone physiology will dominate later on. Implants in the study group were moistened by PRP before insertion; the results showed a significant difference in implant stability favoring the study group 30 days postoperative. However, at the end of the study 90 days postoperative it was found that stability values were similar in the two groups.

In contrast, Thor, et al. (23) reported that implant stability measurements were statistically significantly higher for PRP sites in the anterior maxilla. However, the study did not use the same type of grafting material in the study and the control groups in the anterior maxilla so the author concluded that no obvious positive effects of PRP had been detected.

Regarding labial bone width, it was measured only once after six months postoperative at two fixed points. The reason for not measuring bone width immediately postoperative is that the coronal portion of the implant labial surface was covered only with the graft material, which cannot be considered as a real bone. Therefore, we considered that labial bone width 
immediately postoperative at these two points equals zero and the measured bone width after six months postoperative represent the amount of newly formed bone.

The results of this study showed that the amount of gained bone width in the study group was significantly superior to the control group. This result is explained by the positive effect of platelet rich plasma on bone regeneration. Platelet rich plasma minimizes graft resorption and so enhance the gained bone horizontally.

In accordance with this conclusion, Marukawa, et al. (24) conducted a study on twenty patients to evaluate the effect of PRP on cancellous bone and marrow grafts and concluded that PRP significantly reduces postoperative graft resorption. Furthermore, Eskan, et al. (25) evaluated guided bone regeneration using a cancellous allograft with and without PRP and pointed out that there is a significant increase in bone width gained horizontally in the PRP group. Moreover, Deshpande, et al. (26) evaluated the value of PRP in bone grafting procedures in alveolar cleft patients and the results showed less bone resorption in the study group.

On the other hand, Sakio et al. (27) studied the effect of PRP on bone graft resorption when used to repair alveolar clefts. The results showed no significant value of PRP on bone graft resorption.

Bone radio-density is accurately evaluated through computed tomography CT scans according to Hounsfield scale. However, this study used Cone beam CT for evaluation of bone density. Some authors such as Lee, et al. (28) studied whether the insertion torque resistance of implant correlates with CT and CBCT measurements of bone density and they concluded that CBCT is a reliable method to evaluate bone density.

In contrast, other studies claim that CBCT lacks accurate bone density evaluation. Bone density measurement for the same anatomical position by CBCT and medical CT scanners are not the same (29).

Some authors suggested that the CBCT image could be improved by reconstruction algorithm and alternative corrective methods in order to significantly improve the gray values of CBCT (30).

In this study, the mean percentage of change in labial bone density after six months postoperatively was found to be higher in the study group but statistically there was no significant difference. This non-significance could be a result of limited sample size. However, the fact that the mean percentage change in bone density at the study group (112.52\%) was about twice that of the control group (57.95\%) supports the claim that addition of PRP to the graft material has a positive effect on bone regeneration.

Corresponding to this conclusion, a recent randomized clinical trial that was performed on thirty-two immediately placed implants. A bovine xenograft with and without PRP gel were used as for augmentation of the exposed implant surface. The result showed that after six months postoperative bone density was higher in the PRP group but statistically there was no significant difference $(\mathrm{P}=0.67)$. However, further follow up to 12 months revealed a significant difference $(\mathrm{P}=0.0008)$. (31). On the other hand, Kaushick, et al. (32) studied the effect of PRP when added to hydroxyapatite $+\beta$ tricalcium phosphate for treatment of infra-bony defects. A significant positive effect on radiodensity was found in the PRP group. In addition, Khairy, et al. (33) pointed out that bone grafts PRP mixture was associated with significantly higher bone density after six months post operatively. Moreover, Gupta, et al. (34) evaluated the value of adding PRP to a cancellous autograft for treatment of cleft alveolus and there was a significant increase in bone density favoring the PRP group six months postoperatively.

Roffi, et al. (35) preformed a systematic review on several studies and pointed out that there is not enough evidence to reach a conclusion about the role of PRP in augmentation procedure. More randomized controlled trials are needed to clarify this topic. Another Systematic review by Stähli, et al. (36) concluded that adding PRP to the grafting materials may enhance bone regeneration and may reduce postoperative pain and swelling. However, there is a lack of adequate randomized clinical trials on this topic.

Based on the above, it can be considered that although some results did not show significant difference statistically, it is undeniable that the results of the study group were generally better than those of the control group. In addition, the positive effect of platelet-rich plasma on the gained bone width is clear. Further researches are still needed to evaluate the effect of platelet rich plasma on guided bone regeneration around dental implant. Larger sample population and longer follow up periods are recommended to asses clinical and radiographical parameters

\section{CONCLUSION}

The study concludes that Cerabone ${ }^{\circledR}$ can be used effectively for guided bone regeneration around dental implant in narrow maxillary anterior alveolar ridges. Moreover, the addition of platelet rich plasma has a positive effect on bone regeneration around dental implants.

\section{CONFLICT OF INTERSET}

The authors declare that they have no conflicts of interest.

\section{REFRENCES}

1. Scipioni A, Bruschi GB, Calesini G. The edentulous ridge expansion technique: a five-year study. Int J Periodontics Restorative Dent. 1994;14:451-9

2. Fu JH, Wang HL. Horizontal Bone Augmentation: The Decision Tree. Int J Periodontics Restorative Dent. 2011;31:429-36.

3. Abrahamsson P, Wälivaara D, Isaksson S, Andersson G. Periosteal Expansion Before Local Bone Reconstruction Using a New Technique for Measuring Soft Tissue Profile Stability: A Clinical Study. J Oral Maxillofac Surg. 2012;70:e521-30.

4. Tovar N, Jimbo R, Witek L, Anchieta R, Yoo D, Manne L et al. The physicochemical characterization and in vivo response of micro/nanoporous bioactive ceramic particulate bone graft materials. Mater Sci Eng C Mater Biol Appl. 2014;43:472-80.

5. Lorean A, Mazor Z, Barbu H, Mijiritsky E, Levin L. Nasal Floor Elevation Combined with Dental Implant Placement: A Long-Term Report of up to 86 Months. The Int J Oral Maxillofac Implants. 2014;29:705-708.

6. Murugan R, Panduranga Rao K, Sampath Kumar T S. Heat-deproteinated xenogeneic bone from slaughterhouse waste: Physico-chemical properties. B Mater Sci 2003;26:523-28

7. Huber F, Berger I, McArthur N, Huber C, Kock H, Hillmeier, $\mathrm{J}$ et al. Evaluation of a novel nanocrystalline hydroxyapatite 
paste and a solid hydroxyapatite ceramic for the treatment of critical size bone defects (CSD) in rabbits. J Mater Sci Mater Med. 2007;19:33-8.

8. Cole BJ, Seroyer ST, Filardo G, Bajaj S, Fortier LA. Platelet-rich plasma: where are we now and where are we going? Sports Health. 2010;2:203-10.

9. Marx RE, Carlson ER, Eichstaedt RM, Schimmele SR, Strauss JE, Georgeff KR. Platelet-rich plasma: growth factor enhancement for bone grafts. Oral Surg Oral Med Oral Pathol Oral Radiol Endod. 1998;85:638-646.

10. Christensen D, Karoussis I, Joss A, Hammerle C, Lang N. Simultaneous or staged installation with guided bone augmentation of transmucosal titanium implants. A 3-year prospective cohort study. Clin Oral Implants Res. 2003;14:680-686.

11. Fairbairn P, Leventis M. Protocol for Bone Augmentation with Simultaneous Early Implant Placement: A Retrospective Multicenter Clinical Study. Int J Dent 2015;2015:1-8.

12. Lee J, Park H, Kim J, Choi Y, Kim Y, Huh J et al. A 5year retrospective clinical study of the Dentium implants. J Adv Prosthodont. 2011;3:229.

13. Caiazzo A, Brugnami F, Mehra P. Can placement of an immediate bone level tapered implant and subperiosteal xenograft help maintain bone architecture in esthetic areas?. J Oral Biol Craniofac Res. 2019;9:186-189.

14. Forna D, Forna N, Earar K, Popescu E. Postoperative clinical evolution of edentulous patients treated by guided bone regeneration using xenograft bone substitute and collagen membrane. Mater Plast. 2017;54:312-315.

15. Fukaya M, Ito A. A New Economic Method for Preparing Platelet-rich Plasma. Plast Reconstr Surg Glob Open. 2014;2:e162.

16. Cieślik-Bielecka A, Pierchała M, Królikowska A, Reichert P. Effect of L-PRP treatment on wound healing after surgical skin incision in an experimental animal model. Connect Tissue Res. 2018;59:550-60.

17. Esposito M, Grusovin M, Maghaireh $\mathrm{H}$, Worthington $\mathrm{H}$. Interventions for replacing missing teeth: different times for loading dental implants. Cochrane Database Syst Rev. 2013;28:CD003878

18. Lachmann S, Jäger B, Axmann D, Gomez-Roman G, Groten M, Weber H. Resonance frequency analysis and damping capacity assessment. Clin Oral Implants Res. 2006;17:75-79.

19. Zix J, Hug S, Kessler-Liechti G, Mericske-Stern R. Measurement of dental implant stability by resonance frequency analysis and damping capacity assessment: comparison of both techniques in a clinical trial. Int J Oral Maxillofac Implants. 2008;23:525-530.

20. Monov G, Fuerst G, Tepper G, Watzak G, Zechner W, Watzek G. The effect of platelet-rich plasma upon implant stability measured by resonance frequency analysis in the lower anterior mandibles. Clin Oral Implants Res. 2005;16:461-5.

21. Ergun G, Egilmez F, Cekic-Nagas I, Karaca İ, Bozkaya S. Effect of Platelet-Rich Plasma on the Outcome of Early Loaded Dental Implants: A 3-Year Follow-up Study. Oral Implantol. 2013;39:256-263.

22. Gopinath A, Ravikanth A, Kadiyala K, Thota K, Manne P, Babu M. Effect of platelet rich plasma on stability of dental implants: A prospective comparative clinical study. J NTR Univ Health Sci. 2017;6:107.

23. Thor A, Wannfors K, Sennerby L, Rasmusson L. Reconstruction of the Severely Resorbed Maxilla with Autogenous Bone, Platelet-Rich Plasma, and Implants: 1 Year Results of a Controlled Prospective 5-Year Study. Clin Implant Dent Relat Res. 2005;7:209-220.

24. Marukawa E, Oshina H, Iino G, Morita K, Omura K. Reduction of bone resorption by the application of plateletrich plasma (PRP) in bone grafting of the alveolar cleft. J Craniomaxillofac Surg. 2011;39:278-83.

25. Eskan M, Greenwell H, Hill M, Morton D, Vidal R, Shumway B, et al. Platelet-Rich Plasma-Assisted Guided Bone Regeneration for Ridge Augmentation: A Randomized, Controlled Clinical Trial. J Periodontol. 2014;85:661-8.

26. Deshpande R, Yadav A, Borle R, Kala A, Jajoo S, Thakkar D. Comparative efficacy of autologous alveolar bone grafting with autologous platelet-rich plasma and without platelet-rich plasma in cleft alveolus patients. J Cleft Lip Palate Craniofac Anomal. 2017;4:22.

27. Sakio R, Sakamoto Y, Ogata H, Sakamoto T, Ishii T, Kishi K. Effect of Platelet-Rich Plasma on Bone Grafting of Alveolar Clefts. J Craniofac Surg. 2017;28:486-8.

28. Lee S, Gantes B, Riggs M, Crigger M. Bone density assessments of dental implant sites: 3. Bone quality evaluation during osteotomy and implant placement. Int $\mathrm{J}$ Oral Maxillofac Implants. 2007;22:208-12.

29. Armstrong R. Acceptability of Cone Beam CT vs. MultiDetector CT for 3D Anatomic Model Construction. J Oral Maxillofac Surg. 2006;64:37.

30. Dong $\mathrm{X}$, Petrongolo $\mathrm{M}$, Niu T, Zhu L. Low-Dose and Scatter-Free Cone-Beam CT Imaging Using a Stationary Beam Blocker in a Single Scan: Phantom Studies. Comput Math Methods Med. 2013;2013:1-8.

31. ArRejaie A, Al-Harbi F, Alagl A, Hassan K. Platelet-Rich Plasma Gel Combined with Bovine-Derived Xenograft for the Treatment of Dehiscence Around Immediately Placed Conventionally Loaded Dental Implants in Humans: Cone Beam Computed Tomography and Three-Dimensional Image Evaluation. Int J Oral Maxillofac Implants. 2016; 431-438.

32. Kaushick B, Padmalatha O, Jayakumar N, Varghese S. Treatment of human periodontal infrabony defects with hydroxyapatite $+\beta$ tricalcium phosphate bone graft alone and in combination with platelet rich plasma: A randomized clinical trial. Indian J Dent Res. 2011;22:505.

33. Khairy N, Shendy E, Askar N, El-Rouby D. Effect of platelet rich plasma on bone regeneration in maxillary sinus augmentation (randomized clinical trial). Int J Oral Maxillofac Surg. 2013;42:249-55.

34. Gupta C, Mehrotra D, Mohammad S, Khanna V, Kumar Singh G, Singh $G$ et al. Alveolar bone graft with Platelet Rich Plasma in cleft alveolus. J Oral Biol Craniofac Res. 2013;3:3-8.

35. Roffi A, Filardo G, Kon E, Marcacci M. Does PRP enhance bone integration with grafts, graft substitutes, or implants? A systematic review. BMC Musculoskelet Disord. 2013;14:330. 